\title{
On Film and Television Education for Film and Television Industry
}

\author{
Jing Sun \\ Media and Communication College of Xi’an Peihua University, Xi’an Shaanxi 710125, China
}

Keywords: film and television industry; film and television education; talent cultivation

\begin{abstract}
The rapid development of film and television industry puts forward an urgent demand to the film and television education. However, based on employment of students and feedback of employers, there are still many problems in the talent cultivation. According to the problem, we should think and discuss deeply the cultivation mode of film and television talents, and how to effectively train advanced talents in film and television industry has become the urgent problem to be solved.
\end{abstract}

\section{Introduction}

At present, majors related to film and television in China's comprehensive universities are: drama and film-and-television literature, radio and television editing, and photography. Each major has its own focus, but there are similarity in the curriculum setting. The current film and television industry spurts in its development. For the western region alone, in the past year, more than 300 new film and television enterprises have been established. Faced with the rapid development of the industry, the demand for talent in the industry puts forward more requirements. In order to adapt to the development of the industry, to cultivate what kind of film and television talents, and how to cultivate them have become urgent issues to be solved. The cultivation of talents in film and television has quantitative and qualitative requirements. The qualitative requirement is due to the fact that the film and television talents need to serve the film and television culture industry, and the demand for quantity is because the current film and television industry is not only film and television, but also includes the environment of new media, self-media, and social media, which brings unprecedented opportunities and challenges to film and television industry today, and the demand for film and television talent is also ever-increasing. Xi'an is the window of the western region, as the capital city of Shaanxi, and many film and television colleges and universities are located here. However, in general, the economy in the western region is underdeveloped, and there are huge differences in the education resources, hardware, and software from the eastern region. Film and television companies in western region are also mostly small-scale companies, whose capital and the quality of employees cannot compete with the major film and television companies in the first-tier cities, therefore, it is particularly urgent to cultivate film and television talents. Xi'an also has natural advantages with rich educational resources, as the city with so many colleges and universities after Beijing and Shanghai. Comprehensive universities have established media and film-and-television majors with many talented people. The cultivation of film and television talents has become an effective method to provide powerful force for the film and television industry

There are many factors that contribute to the success of an outstanding film and television work, inevitable, accidental, common, or individual. The creation of film and television requires the cooperation of multiple occupations, which is also influenced by many factors, including the producer, Party A, director, audience and etc. This is a creative process with cooperation.

\section{Problems in the creation of film and television by students}

\subsection{Screenplay}

There are always some problems in screenplay of students' works. For example, students lack the understanding of story form in screenplay creation. They are not clear about what exactly the form of the "story" is in the process of screenplay creation, and cannot break away from writing patterns 
for over years. In general, the format of their screenplay is always normative, and they fail to write screenplay according to the "scene", lack of the awareness of "scene", thus, sometimes they even write several scenes in one paragraph. Besides, their screenplay is separated from life. Life is the source of screenplay creation. However, students do not have so much life experiences, and their works are separated from life. Common problems include the empty content and weak logic, which cannot impress the audience and cannot resonate with the audience. For instance, students' favorite theme is "campus love story", which generally is close to their age and their life. Whereas, there are few of them can create excellent works. In the screenplay creation, students often work behind closed doors, just relying on the enthusiasm of "All wishes come true". They do not pay attention to the life and lack the basis of life. Thus, there is not creative thinking and fresh elements in their stories created; the stories lack logic, novelty and attraction, far away from basic life and immature, and words and language are not fluent with many faulty wording or formulation, and words failing to express the idea. We should pay attention to cultivating students' sensibility and guide them to discover themselves, know themselves, understand themselves and go deep into the thick of life. The marketability of theme selected is not strong enough. Although their screenplays created are varied, there are some common problems. The screenplays they created are ordinary and long-winded; lack of dramatic conflict; their writing skills are poor without the capability of scene setting; and screenplays are usually not storytelling. In addition, students cannot distinguish the difference in theme selection in film and television, the theme of film is always novel with rapid rhythm and concise plot, whereas, plot of television is more close to life, including detective, crime detection, urban youth and other types. Besides, there is few conflicts setting in screenplays. For instance, they often set one or two conflicts in screenplays. In fact, mature screenplay need a climax every 15 minutes. The screenplays of students, however, are not fierce without suspense. Scene setting is insufficient in their screenplays, which is the weak part for students. For example, the atmosphere of the scene is not shown, the purpose of characters in the scene is not clear, the drama objective of the scene and the role it plays in the overall screenplay are not clear. As for the dialogue of characters, the dialogues created by students often cannot reflect the personality, identity, occupation of characters; For example, it can often be seen in students' work that a cleaner talk his philosophy like a book. Besides, the dialogue is not helpful in image-building of characters, the development of plot, the consideration of overall scene and the integration of the whole plot. In terms of characterization, a mature screenplay is usually full of plentiful stories, vivid characters with main characters, minor characters, and supporting characters, and they closely connect, echo and complement each other. But only main characters are strongly rendered, other characters ignored, which results in the extremely unbalanced characterization. They cannot handle the relationship of characterization and plot structure, in other words, they do not understand deeply the relationship, and cannot handle it perfectly. The development of clues is not balanced. In generally, multiple story lines develop in parallel in a screenplay, which enrich the work itself, increase the attraction, and adjust the rhythm and atmosphere. However, students often cannot manage many clues at the same time in the process of creation, which leads to unbalanced development of clues with monotonous and awkward stories. The top-heavy screenplay is the phenomenon that only the beginning is focused to depict and the process omitted to the end of story directly, lack of frames and montage conception.

\subsection{Shooting}

Students are often immature in the shooting technology at the beginning. There is a huge difference between frames in their mind and frames they shoot, especially, the shooting effect of indoor scene, rain scene, and night scene is not ideal; most of students the Digital Single Lens Reflex for shooting, so the moving shots are not ideal; their grasp of the field of shooting scale is not in place, and they cannot fully understand and appropriately use the fied of shooting scale, resulting in imperfect shots; pickup problems. Film and television major in comprehensive university cannot divide majors like professional schools as detailed as possible, so problems in sound have been quite prominent, especially in the empty indoor and outdoor, the pick-up of the 
corresponding period has always been the shortcoming for students. Lighting problems. Their shooting of natural light environment is generally more ideal, however, shooting of indoor and night scene is generally worse.

\subsection{Film editing}

The hue and style of films edited by students are often not uniform, which also has a certain relationship with the shooting in earlier stage. The not-in-place lighting, the high noisy point in the night scenes, the laggard rhythm, the less prominent characterization, etc., are common problems.

\section{Measures to solve problems}

In the current teaching, practice has been emphasized in film and television majors, and application-oriented teaching has been promoted. However, based on halfway effects obtained so far, further optimization need to be conducted.

\subsection{Necessary market and industry cultivation in film and television majors}

At present, teachers of film and television courses basically use theoretical teaching, accompanied by practice, but not effective. In general, teachers usually conducts theoretical teaching based on the teaching materials, and then conducts corresponding practical exercises. The works created by students usually include the training on students' creative thinking, story structure, montage conception, and so on. Usually teachers guide the corresponding characterization, story structure, montage conception, scene setting, and dialogue design for students according to their interests. Teachers generally seldom impose compulsory rules on theme of works, students often tend to make perceptual and stream-of-consciousness works, so there is a big gap with the needs of the entire film and television industry, and works of students are hard to be adopted by the film and television enterprises.

The school-running orientation of college and universities should be clear, and college and universities of "world-class universities and world-class disciplines" should be distinguished from applied technology-oriented universities in film and television talent training. From 2014, China began to vigorously promote the construction of applied technology-oriented universities. Market awareness and industrial characteristics shall be cultivated in the teaching of because of the strongly professional practice of film and television media majors, in order to guide students to grasp the characteristics and operation of film and television market and industry, which is beneficial for the graduation and employment of students. Break away from "ivory tower" thinking and pretentious creation is the major task.

\subsection{Interdisciplinary cooperation}

The interdisciplinary cooperation in film and television course shall be emphasized. Film and television works is the accomplishment of cooperative creation. The interdisciplinary cooperation of students shall be trained in the teaching. We can cooperate with drama and photography majors, drama majors and broadcasting majors, drama majors and the producer director majors to show the original works in a three-dimensional and complete presentation to increase the attraction of works with their own specialties.

\subsection{The “innovative and entrepreneurial” practice teaching}

Innovation and entrepreneurship are the spirit advocated by our country at present, which also applies to the scriptwriter talent training of film and television majors. First of all, we can take innovation and entrepreneurship competition for college students each year as an opportunity to inspire students' enthusiasm for creation. If selected, there will be a certain amount of capital injection, which will promote the creativity of students to some extent. There is guidance of teachers in big innovation and entrepreneurship project to help the creation of works. "Internet Plus" is also an effective platform for students to apply for competitions, cultivate entrepreneurial awareness, and incubate projects. It is proved that many students who graduate from film and 
television majors start their own business, from studios to companies, thus finding a job is no longer the only way.

\subsection{The cooperation between school and enterprise}

The surge of film and television industry will inevitably require a large number of film and television practitioners. In terms of the scriptwriter, the number of well-known scriptwriters is very small. For small and medium-sized film and television enterprises in the western region, it is not the best policy to spend huge sums of money to hire well-known scriptwriters. First of all, well-known screenwriters do not necessarily have enough energy to devote themselves fully to the small and medium-sized film and television companies in the western film and television industry. For such companies, it is relatively easy to get out of control, which is not just a movie or television play, but the depressed state of the whole company. It is a better way to discover the indigenous new forces. In the teaching, students are required to create works for the market. School-enterprise cooperation can be described as a win-win situation, and the specific approach is to carry out the school-enterprise cooperation to provide many projects. Universities should sign corresponding cooperation with film and television companies who put forward their script positioning, demand, the audience, film type and style. Teachers integrate these requirements into teaching in the classroom to guide students to make corresponding creations according to the requirements and conduct class discussions in the classroom, teachers give opinions, and the students modify, polish, and improve their works. Then, each class selects the top three scripts to be sent to the film and television company to review and decide. If adopted, students will get paid correspondingly. In this way, the creative interest will be improved, the ability to face the market of students trained, and a certain amount of compensation provided for students. For the film and television companies, the thinking of students is flexible with passion and creation, and the process is cost-effective. However, students lack experience and market awareness, and the control and teaching of teachers in the classroom can make up for the shortcomings and creative works. Therefore, it can be said to be worthwhile. Tap potential young talents, develop new forces, create a good film and television ecological environment, and encourage the originality. In shooting and post-production, select students who are outstanding in the class to be photography assistants and post-production assistants to follow a project in the whole process. Students with different interests are trained to have experience in complete production process of film and television industry, and awareness of types, awareness of platform, and awareness of business transformation.

Problems confronted in the current talent cultivation of film and television majors have been summarized, and some solutions and measures have been proposed according to practical teaching experience over years. Based on the requirements of market, the exploration of reasonable practical teaching in film and television education will greatly improve the capability of practical creation of students, and cultivate forces in creation for film and television industry.

\section{Acknowledgments}

Fund program: 2017 Shaanxi Province education science planning issue: Study on "innovative and entrepreneurial" practical teaching mode of film and television industry in western region under the background of "Internet Plus" (Issue No. SGH17H466).

\section{References}

[1] Peng Kan. The System of Hollywood Film Scenario Exploitation [J]. Contemporary Cinema, 2014(07):25-30.

[2] Wang Wenna. Where Should Scriptwriting Major Go in the IP Tide? [J]. Art Education, 2016(04):36-42. 